\title{
FINITE ELEMENT SIMULATION OF ACOUSTIC ATTENUATION PERFORMANCE OF ELLIPTICAL MUFFLER CHAMBERS
}

\author{
Abdullah A. Dhaiban, M-Emad S. Soliman, and M.G. El- \\ Sebaie \\ Mech. Engineering Dept., Faculty of Engineering, Assiut University, \\ Assiut, Egypt
}

(Received September 27, 2011 Accepted October 24, 2011)

\begin{abstract}
A three-dimensional finite element analysis has been implemented to predict the transmission loss of an elliptic expansion chamber muffler for a given frequency range. Finite element models have been established by ANSYS 12.0.1. Results obtained from the model were compared with both experimental data obtained from previous work of Gerges et al. [1] . Comparison showed an excellent agreement between modeling results and experimental data. Six muffler configurations of different major/minor axis ratios of elliptic expansion chamber $(a / b)$, with equal chamber volume have been modeled. Results demonstrated the ability of FEM to represent the acoustic attenuation performance of acoustical muffler. It also showed the effect of $(a / b)$ ratio on the cut-off frequency due to multidimensional modes propagation. The FEM results were interpreted in various muffler configurations to determine the relationship between the number of domes in transmission loss characteristic curve and $(a / b)$ ratio.
\end{abstract}

KEYWORDS: expansion chamber muffler, finite element modeling, transmission loss

\section{INTRODUCTION}

There are a lot of noise producing machines which produce noise such as aircrafts, pumps, electrical generators, automotives...etc. Exhaust noise of automotive engines is the main component of noise pollution of the urban environment [2]. Exhaust gases repeatedly released from the internal combustion engine at high pressures cause high pressure levels of sound waves. So, designing an effective acoustical muffler and/or silencer to attenuate sound pressure levels is becoming a basic requirement. The finite element method (FEM) has proved to be suitable to predict the acoustic attenuation performance of reactive mufflers with any given geometry and FEM predictions have shown good agreement with experiments and three dimensional analytical results for several muffler configurations [3-5].

Munjal [6] used the transfer matrix method to study the aerodynamic noise control problems on the basis of the plane wave theory. However, this method suits only one dimensional systems and the higher-order mode effects in wave propagation are neglected. The higher-order modes can significantly affect the performance of expansion chamber mufflers [7], [8] .Kirby [9] also added that, plane wave approach is inaccurate when perforated pipes of low porosity are present. Above approximately $500 \mathrm{~Hz}$, it is necessary to include higher order modes in the modelling methodology. 
Gerges et al. [1] concluded that it is possible to use the transfer matrix method for predicting the acoustic behavior of mufflers in the low frequency range. Therefore, the method can be used to design a prototype muffler that would reduce the noise produced at the firing engine frequency and its first few harmonics, where the effects of higher order modes can be neglected. Mehdizadeh [10] stated that a multi-dimensional approach is required for the accurate prediction of acoustic attenuation performance of a muffler; and the FEM is suitable to predict the acoustic performance of reactive muffler with any given geometry. Wu et al. [7] mentioned that a finite element method (FEM) has also been involved in the study fields of higher-order modes which are also based on three-dimensional acoustical analysis.

Denia et al. [11] mentioned that elliptical geometry is widely used in automotive mufflers. However, there are relatively few reported studies of its acoustic attenuation performance. They also studied the problem of wave propagation in elliptical chamber mufflers from several points of view. The solution of the wave equation in elliptic co-ordinates is expressed in terms of the Mathieu functions, obtaining the natural frequencies and mode shapes. The modal superposition technique and the point source method have been applied to a number of elliptical mufflers (expansion chambers and reversing chambers) to obtain their transmission loss. The results are compared with those obtained from the finite element method and from experiments, showing a good agreement. Also the boundary element method and the finite element method (FEM) are the most interesting ones.

One of the major advantages of the FEM is the possibility to analyze problems with arbitrary geometry and general boundary conditions, but at the cost of long computation times if sufficient accuracy is desired at high frequencies, due to the large number of elements required [11]. FEM requires high computational and memory resources particularly at higher frequency, but the availability of high speed computers, also using domain decomposition and parallel processing techniques have led to overcome this defect [5]. Also dividing the solution scheme into models with different element size, coarser mesh model for lower frequencies and finer model mesh for higher frequencies reduce the analyses time as mentioned by Bilawchulk [12].

The main objective of the present study is to build a three dimensional finite element model (3D-FEM) for elliptical expansion chambers to study the effect of external geometry specifically major diameter to minor diameter of expansion chamber on acoustic attenuation performance.

\section{EXPANSION CHAMBERS}

The reactive or reflective mufflers use the phenomenon of destructive interference to reduce noise. This means that they are designed so that the sound waves produced by an engine partially cancel themselves out in the muffler. For complete destructive interference to occur a reflected pressure wave of equal amplitude and 180 degrees out of phase needs to collide with the transmitted pressure wave. Reflections occur where there is a change in geometry or an area discontinuity [13].

The most basic type of silencing element that may be used for intake and exhaust mufflers is the expansion chamber muffler. It consists of an inlet tube, an expansion chamber and an outlet tube as shown in Figure 1. The inlet and outlet tubes may be coaxial known as a concentric expansion chamber or offset known as an offset 
expansion chamber [8]. Expansion chambers are efficient in attenuating low frequency sound, which makes them ideal for automotive applications. Expansion chamber mufflers have been widely studied and results show that the larger the expansion ratio $m$ (area of expansion chamber/ area of inlet (outlet) tube) the greater the transmission loss. The length of the chamber should be at least 1.5 times its diameter. Transmission loss (TL) defines in terms of a logarithmic ratio between the acoustic power incident on the muffler and the acoustic power transmitted by the muffler [12], when the termination is anechoic [14]. Transmission loss (TL) can be calculated as:

$$
T L=10 \log _{10}\left[1+\frac{1}{4}\left(m-\frac{1}{m}\right)^{2} \sin ^{2} k l\right]
$$

Where $m=A_{\text {expansion }} / A_{\text {pipe }}$ is the expansion ratio, $k=2 \pi f / c$ is the wave number and $l$ is the length of the expansion chamber. Here, $f$ is the frequency, $c$ is the speed of sound, and $A_{\text {expansion }}$ is the cross sectional area to which the wave from the pipe with cross-sectional area $A_{\text {pipe }}$ is expanded.

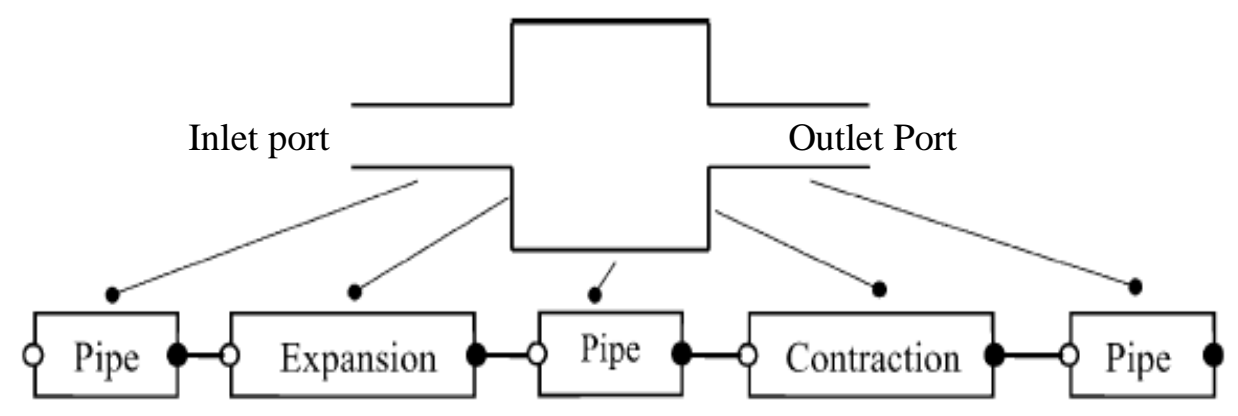

Figure 1. Typical expansion chamber

\section{FINITE ELEMENT MODEL}

A harmonic analysis, by definition, assumes that any applied load varies harmonically (sinusoidally) with time. To completely specify a harmonic load in an acoustic analysis, two pieces of information are usually required the amplitude and the forcing frequency [12]. In the finite element method the entire three-dimensional domain has to be discretized and modeled with volume elements.

Acoustic analysis in ANSYS can be solved by performing harmonic analysis. The analysis calculates the pressure distribution in the fluid due to a harmonic load. The procedure for a harmonic acoustic analysis consists of three main steps:

- $\quad$ Model Building

- Applying boundary conditions and loads and obtaining solution

- $\quad$ Review results

In deriving the discretized acoustic wave equation, there are some necessary assumptions: 
- The fluid is compressible, but only relatively small pressure changes with respect to the mean pressure are allowed.

- $\quad$ The fluid is inviscid (no viscous dissipation).

- There is no mean flow of the fluid.

- The mean density and mean equilibrium pressure are uniform throughout the fluid.

\subsection{Model Building}

The factor that directly affects the number of equations, and therefore the time required, is the number of elements in the model. Another factor that affects the number of elements is the size of each element. The element size has a direct relation to the frequency range that can be accurately modeled by the system. In order to accurately interpolate the sinusoidal nature of sound waves, a minimum of 5 or 6 and maximum 20 or 25 elements per wavelength are required [12], [15]. With this constraint, it can be seen that as the frequency increases the element size needs to be made smaller to properly solve the system at high frequencies. On other time reduction technique involves dividing the solution scheme into models with different element sizes. The reason this is beneficial, is that for the lower frequencies, it is possible to have a much coarser mesh [12].

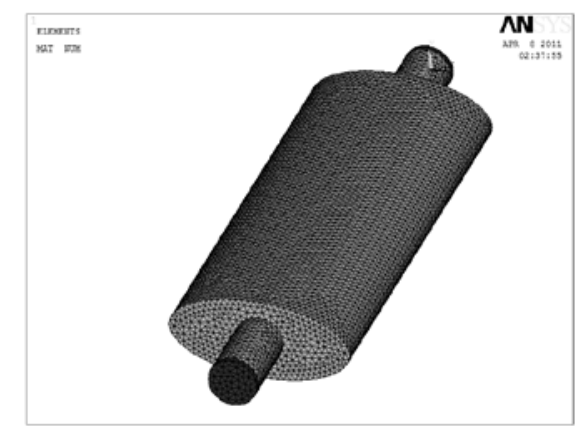

Fig. 2. Typical FE model of an elliptical expansion chamber

In the present study each model was meshed using tetrahedral FLUID30 element. The resulting mesh size produces 10 elements per acoustic wave length at the upper band of the frequency range being analyzed.

A good FEA model should be able not only to mathematically represent the physical system as accurate as possible but also to avoid unnecessary computational cost as much as possible. Figure 2 shows an FE model of an elliptic expansion chamber.

\subsection{Boundary Conditions, Loads and FEM Solution}

The main goal of an FEA is to examine how a structure or component responds to certain loading conditions. Therefore, specifying the proper loading conditions is also a key step in the analysis including certain boundary condition. Traditional method is applied to calculate the transmission loss as shown in Fig. 3. For both geometries, the 
inlet and outlet sections have the characteristic impedance $(z=\rho * c)$ boundary condition applied. This model is a completely anechoic source and termination. For physical testing, the source and termination ends of the tube are stuffed with absorptive material to minimize reflections and, as close as possible, to mimic an anechoic impedance. Also, for both geometries, the inlet section is given a unit velocity amplitude to model a sound source. All other surfaces are modeled as "acoustically hard'” by default [16].
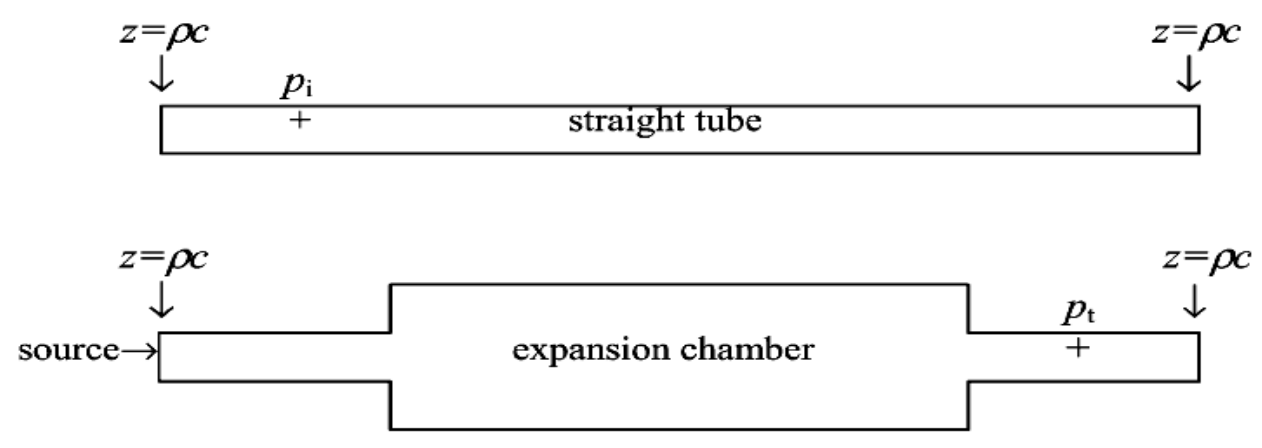

Fig. 3. Traditional method measurement points [16]

As long as the inlet and outlet regions of the silencer are of the same cross section, and the properties of the fluid (density, temperature) do not change, then the TL can be expressed as:

$$
T L=20 \log _{10}\left|\frac{p_{i}}{p_{r e}} \frac{p_{r e}}{p_{t}}\right|=20 \log _{10}\left|\frac{p_{i}}{p_{t}}\right|
$$

In the solution phase of the analysis, the computer takes over and solves the simultaneous set of equations that the finite-element method generates.

\subsection{Procedure for Result Review}

The results include nodal DOF values, which form the primary solution, and derived values, which form the element solution. In harmonic acoustic analysis the pressure distribution in the model is calculated due to a harmonic load.

\section{FEM RESULTS}

Figure 4 shows the general geometry of a simple elliptic expansion chamber. In the present study six elliptic expansion chamber muffler configurations were modeled as described in Table 1. For all configurations the expansion chamber length $(l)$ and the inlet and outlet tube diameter (d) were kept constant at $0.42 \mathrm{~m}$ and $0.0477 \mathrm{~m}$ respectively these dimensions were selected based on an experimental model by Gerges et al [1]. The transmission loss was calculated for each model. All dimensions in Table 1 are given in meters. 

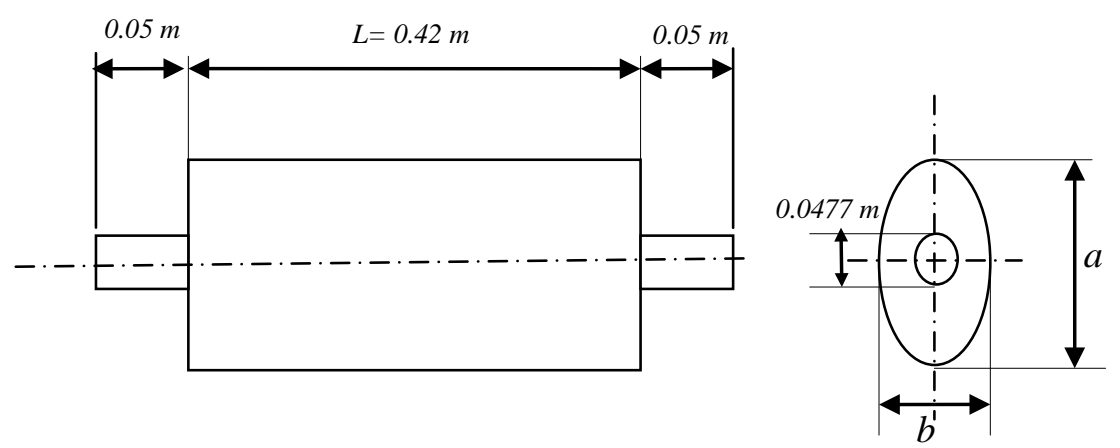

Fig. 4. General geometry of a simple elliptic expansion chamber

Table 1: Elliptic expansion chamber model configurations

\begin{tabular}{cccc}
\hline Model & a/b & a & b \\
\hline 1 & 1.5 & 0.148 & 0.0987 \\
2 & 2.5 & 0.191 & 0.076 \\
3 & 3.5 & 0.226 & 0.0646 \\
4 & 4.5 & 0.258 & 0.0575 \\
5 & 5.5 & 0.286 & 0.052 \\
6 & 6.5 & 0.312 & 0.0477 \\
\hline
\end{tabular}

Figure 5 compares the experimental values, transfer matrix method results given by Gerges et al. [1] and numerical results obtained from the present FEM modeling to verify the accuracy of FEM. An excellent agreement of FEM results with experimental values over the entire frequency range, whereas transfer matrix method (TMM) is in good agreement only up to point next to the cut-off frequency. This demonstrates that the accuracy of FE model aginst the TMM method and enhance the ability of FEM in modeling of acoustical muffler performance including the effects of multidimensional modes propagation.

Figure 6 compares the transmission loss characteristics of both FE model and analytical method obtained by one dimensional plane wave theory for a circular expansion chamber. Results show high agreement between FE results and analytical result up to the cut-off frequency ( $\mathrm{f}=1.84 \mathrm{c} / \pi \mathrm{d}$ ). After that, multidimensional modes propagate without attenuation, as shown by the FE model results. Plane wave theory results are only valid up to the cut-off frequency because it does not include the effect of multidimensional wave mode. Figure 7 compares the transmission loss characteristics obtained by FE for both a circular and an elliptical expansion chamber. 


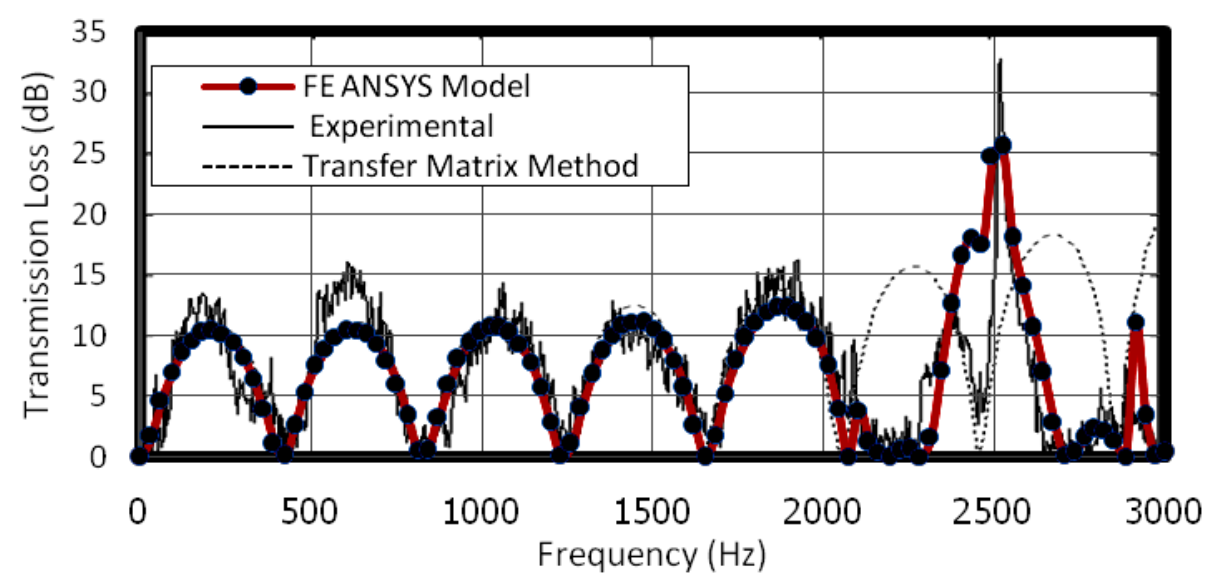

Fig. 5. Transmission loss curves used for model verification of a simple expansion chamber muffler

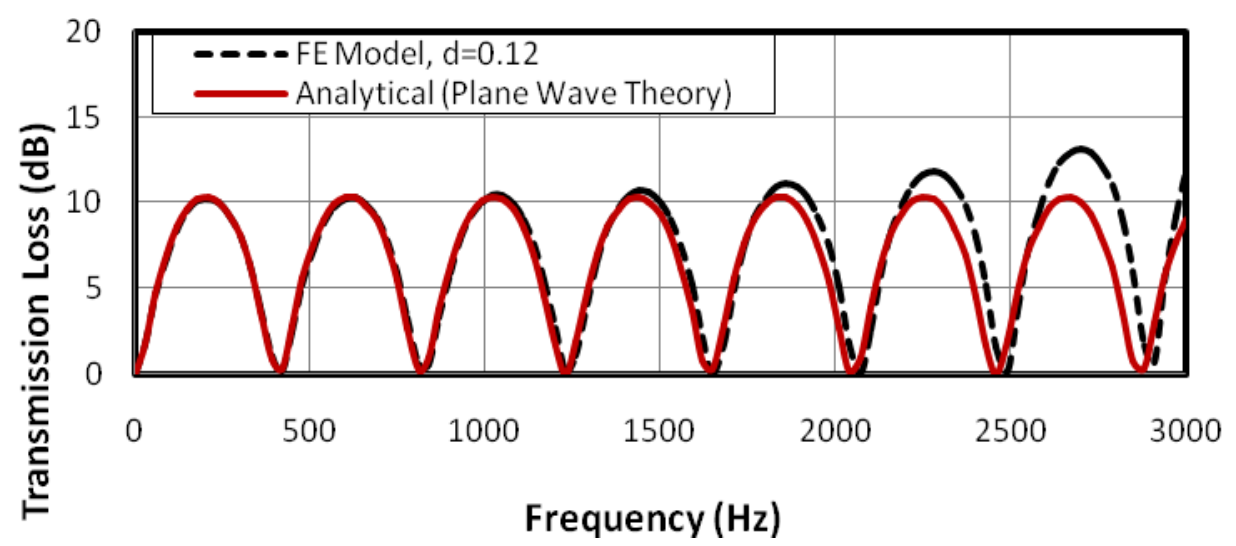

Fig. 6 Comparison of TL for a circular expansion chamber using FEM and analytical plane wave theory 


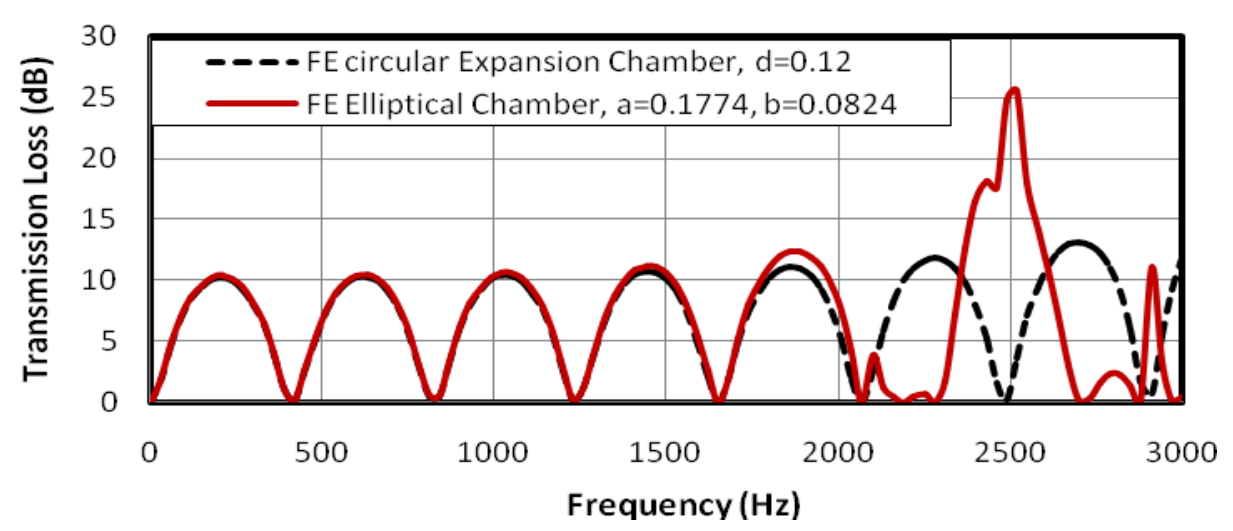

Fig. 7 Comparison of TL for equal volume of circular and Elliptical expansion chambers

A simplified formula for the first cut-off frequency of an elliptic chamber has been given by Tsuyoshi as Gerges mentioned [1] as $\left(f_{c}=\beta c / \pi a\right)$, Where the factor $\beta$ is calculated in terms of the tube eccentricity, e, according to Fig. 8 . The eccentricity of an ellipse is defined as $e=\left(1-b^{2} / a^{2}\right)^{1 / 2}$, Where $a$ is the length of the major diameter and $\mathrm{b}$ is the length of the minor diameter.

Table 2 compares the first cut-off frequency obtained analytically and by FEM. Same data is plotted in Fig. 9. Deviation between the two methods is caused by the assumptions in the simplified analytical formula.

Table 2 Comparison of Cut-off Frequency Obtained from Analytical Formula and FE Model

\begin{tabular}{|c|c|c|c|c|c|c|}
\hline Model & $(a / b)$ & $A, m$ & $e$ & $\beta$ & $\begin{array}{c}f_{c} \\
\text { Analytical }\end{array}$ & $\begin{array}{c}f_{c} \\
\text { FEM }\end{array}$ \\
\hline circular & 1 & 0.12 & & & 1678 & \\
\hline Model (1) & 1.5 & 0.148 & 0.744722 & 3.36 & 2485 & 2495 \\
\hline Model (2) & 2.5 & 0.191 & 0.916206 & 3.458 & 1982 & 1850 \\
\hline Model (3) & 3.5 & 0.226 & 0.958169 & 3.479 & 1685 & 1650 \\
\hline Model (4) & 4.5 & 0.258 & 0.975588 & 3.487 & 1479 & 1510 \\
\hline Model (5) & 5.5 & 0.286 & 0.983901 & 3.491 & 1336 & 1250 \\
\hline Model (6) & 6.5 & 0.312 & 0.98866 & 3.494 & 1226 & 1000 \\
\hline
\end{tabular}

Assumptions in the simplified analytical formula. 


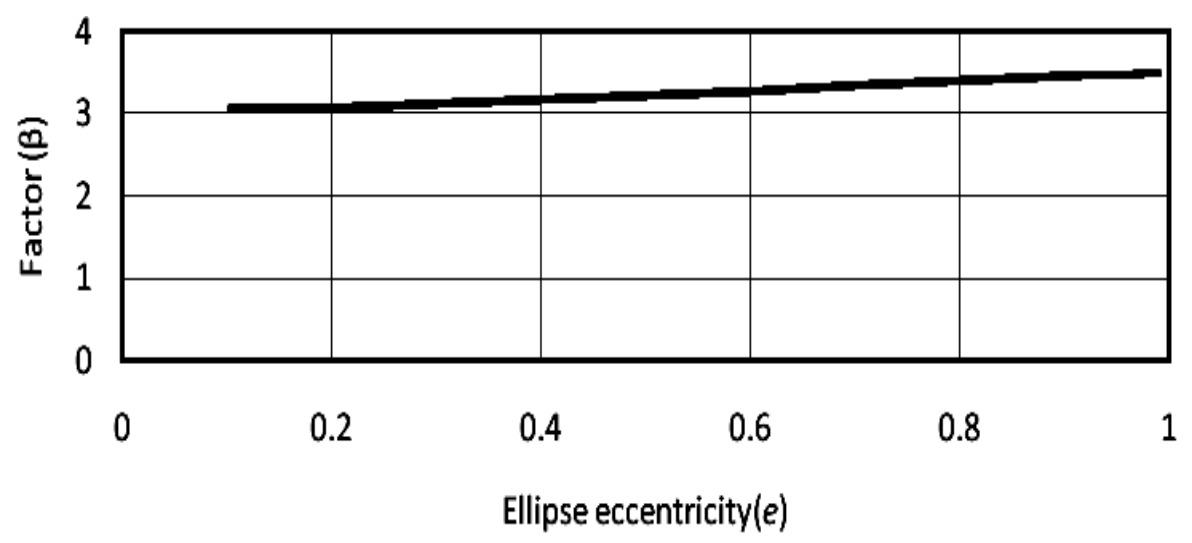

Figure 8. Representation of the factor $\beta$ as a function of ellipse eccentricity $(e)$

Figure 10 compares the transmission loss characteristics for six different configurations of elliptic chambers having different $(\mathrm{a} / \mathrm{b})$ ratios. The figure also shows that with increased $(\mathrm{a} / \mathrm{b})$ ratio, the cut-off frequency decreases.

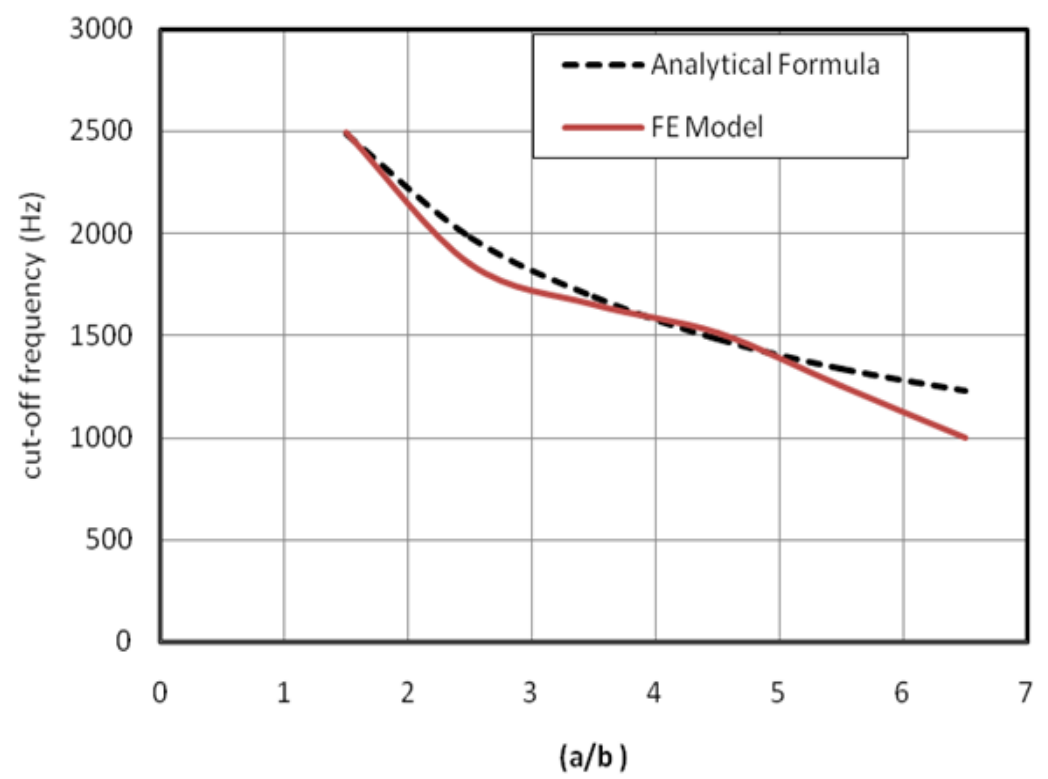

Fig. 9. Comparison of cut-off frequency obtained from analytical formula and FE model

Figure 11 shows the effect of $(\mathrm{a} / \mathrm{b})$ ratio on the number of repeating domes. Some of the trends found in circular chambers are quite similar to those that appear in the elliptic case. Results are approximately close to the number of domes obtained from the analytical formula of circular section expansion chamber obtained by Selamet and Radavich [17] as number of domes $=2.44(L / D)$. Equation (3) represents the 
number of domes in elliptic section expansion chamber with the same cross section area in circular case.

number of domes $=2.1(\mathrm{~L} / \mathrm{a})$

Where: $a$ is the major diameter of the ellipse.

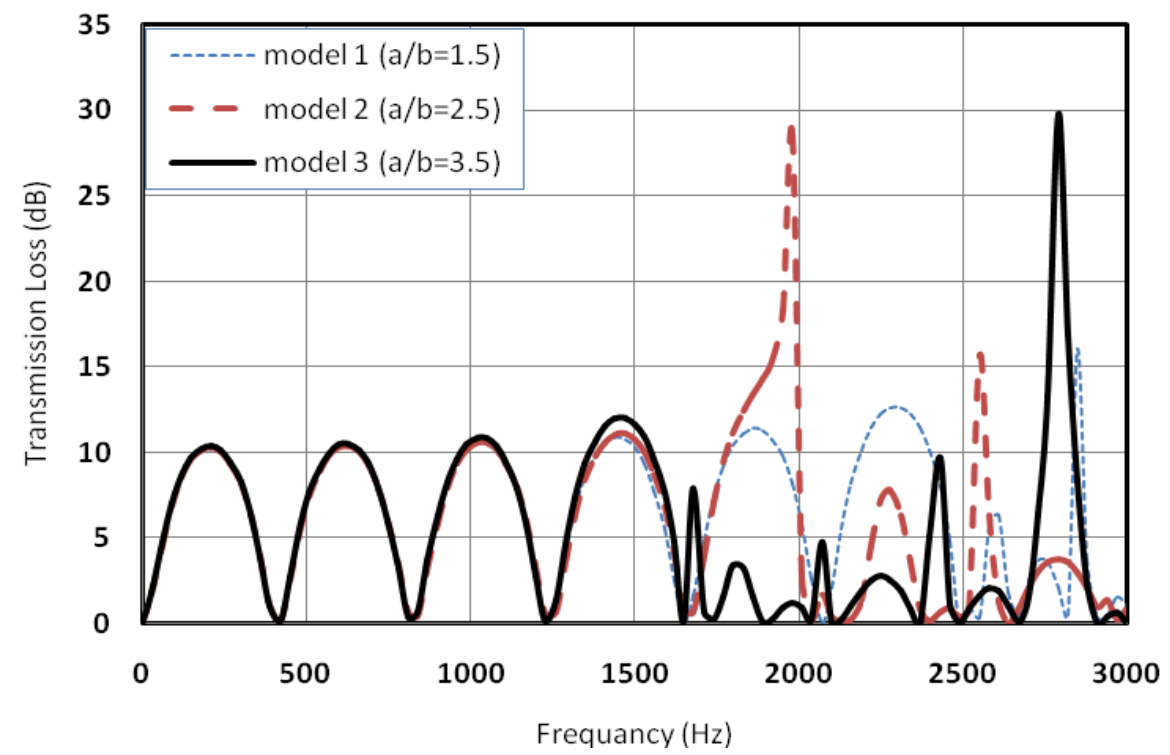

(a) Models 1,2 and 3

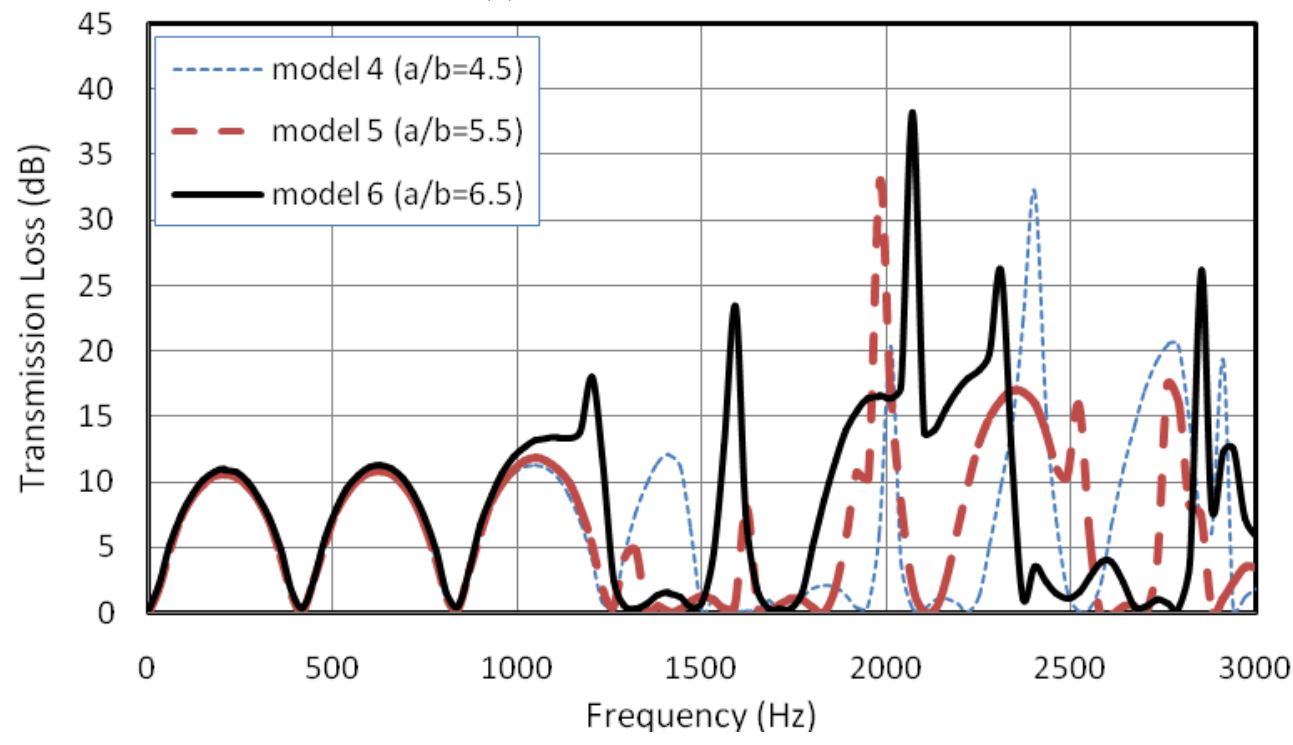




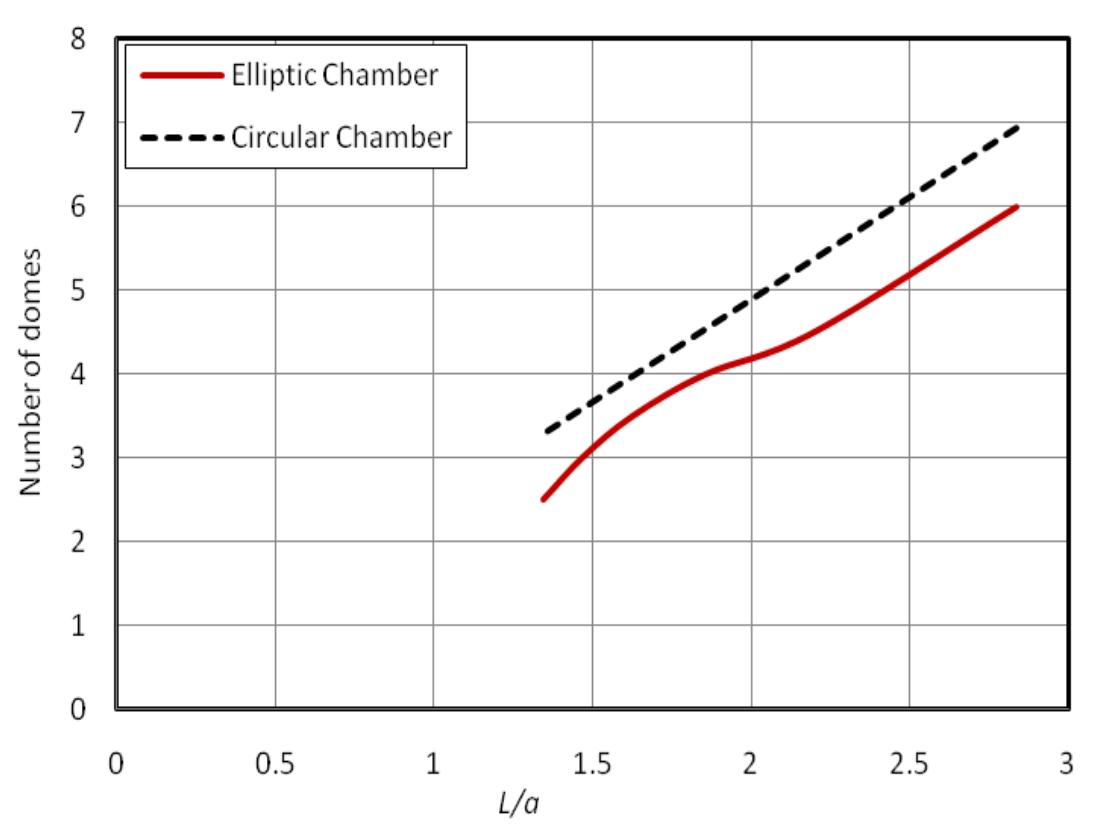

Figure 11. The predicted number of FE model transmission loss domes versus the length/major diameter $(L / a)$ ratio

\section{CONCLUSION}

An accurate three-dimensional finite element modeling of an elliptic expansion chamber has been established. The model demonstrates the ability and accuracy of the FEM in modeling of acoustic wave attenuation in an elliptic expansion chamber muffler. Six different configurations of major/minor axis ratios of elliptic expansion chamber $(a / b)$, has been modeled. Results showed that the ratio $(\mathrm{a} / \mathrm{b})$ has an effect on the transmission loss characteristics of the muffler. Finite element method models take into account the effects of multidimensional modes in attenuation performance whereas plane wave theory is valid only up to the cut-off frequency. Results show that the $(\mathrm{a} / \mathrm{b})$ ratio has a major effect on the number of domes in transmission loss characteristics.

Results obtained encourage extending the application of the FEM to more complex shapes where other methods have failed to do so accurately, and studying the effects of extended tube and perforated tubes inside the expansion chamber, also temperature effects can be added to the model to increase its accuracy.

\section{REFERENCES}

[1] S.N.Y. Gerges, R. Jordan, F.A. Thieme, J.L. Bento Coelho, and J.P. Arenas, "Muffler Modeling by Transfer Matrix Method and experimental Verification," Journal of the Brazilian Society of Mechanical Sciences and Engineering, vol. 27, Jun. 2005.

[2] M.L. Munjal, "Analysis and Design of Mufflers—an Overview of Research At the Indian Institute of Science,” Journal of Sound and Vibration, vol. 211, Apr. 1998, pp. 425-433. 
[3] A. Selamet and Z. L. Ji, "Acoustic Attenuation Performance Of Circular Expansion Chambers With Offset Inlet / Outlet : I . Analytical Approach,” Journal of Sound and Vibration, vol. 213, 1998, pp. 601-617.

[4] A. Selamet, Z. Ji, and P.M. Parav, "Acoustic Attenuation Performance of Circular Expansion Chambers with Offset Inlet / Outlet : II . Comparison with Experimental and Computational Studies,” Journal of Sound and Vibration, vol. 213, 1998, pp. 619-641.

[5] O.Z. Mehdizadeh and M. Paraschivoiu, "A Three-Dimensional Finite Element Approach for Predicting the Transmission Loss in Mufflers and Silencers with no Mean Flow,” Applied Acoustics, vol. 66, 2005, pp. 902-918.

[6] M.L. Munjal, Acoustics of Ducts and Mufflers, 1987.

[7] C.J. Wu, X.J. Wang, and H.B. Tang, "Transmission loss prediction on SIDO and DISO expansion-chamber mufflers with rectangular section by using the collocation approach,” International Journal of Mechanical Sciences, vol. 49, 2007, pp. 872-877.

[8] D. Potente, "General Design Principles for an Automotive Muffler," Proceding of acoustic, Busselton, Westen Australia: 2005, pp. 153-158.

[9] R. Kirby, "A Comparison Between Analytic and Numerical Methods for Modelling Automotive Dissipative Silencers with Mean Flow," Journal of Sound and Vibration, vol. 325, 2009, pp. 565-582.

[10] O.Z. Mehdizadeh, "Simulation of Acoustic Muffler and Silencer,",Ph.D. thesis, University of Toronto, 2005.

[11] F.D. Denia, J. Albelda, and F.J. Fuenmayor, "Acoustic Behaviour of Elliptical Chamber Mufflers," Journal of Sound and Vibration, vol. 241, 2001, pp. 401-421.

[12] S. Bilawchulk, "Finite Element Modeling of Acoustical Silence,",M.Sc. thesis, Alberet University, 2002.

[13] U. Ingard, Noise Reduction Analysis, Jones And Bartlett, 2010.

[14] Justin D. Keske, "Investigation of A Semi-Active Muffler System with Implementation on A Snowmobile,",Ph.D thesis, Michigan Technological University, 2009.

[15] P. Jones and N. Kessissoglou, "An Evaluation Of Current Commercial Acoustic Fea Software For Modelling Small Complex Muffler Geometries : Prediction Vs Experiment," 2009, pp. 1-6.

[16] S. Bilawchuk and K.R. Fyfe, "Comparison and implementation of the various numerical methods used for calculating transmission loss in silencer systems," 2003.

[17] A. Selamet and P.M. Radavich, "The Effect of Length on the Acoustic Attenuation Performance of Concentric Expansion Chambers: an Analytical, Computational and Experimental Investigation,” Journal of Sound and Vibration, vol. 201, Apr. 1997, pp. 407-426. 


\section{تمثيل اداء غرفة كاتم صوث (شكمان) بيضاوي المقطع بإستخدام العناصر المحدودة}

في هذا البحث تم بناء نموذج لغرفة كاتم صوت (شكمان) بيضاوي المقطع باستخدام طريقة العناصر المحدودة

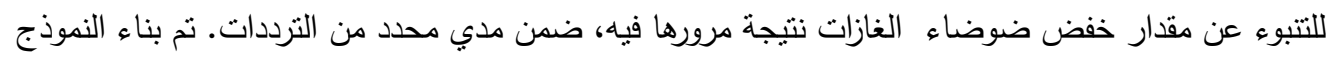
بإستخدام برنامج .ANSYS 12.0.1 واظهرت النتائج تطابقاً ممتازاً مع النتائج العملية مما يدلل على مقدرة طريقة

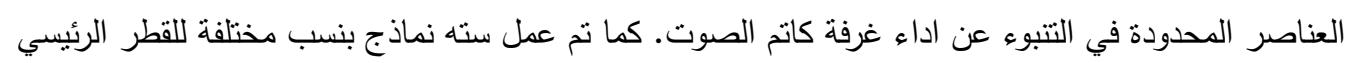
الى القطر الثانوي لغرفة العادم بيضاوية المقطع (a/b) مع الاحتفاظ بحجم ثابت في جميع النماذج حيث اثبتت النتائج ناثير (a/b) على قيمة التردد التي تبدا بعده انتشار موجة الصوت بانماط متعددة الابعاد (ثنائية وثلاثية) وكذلك تاثير (a/b) على عدد القباب المنتظمة في منحنى خصائص خفض الضوضاء. 